\title{
P01.03. A machine classification measure of meditation ability
}

\author{
A McCollough*, K Hild, H Wabeh, B Oken \\ From International Research Congress on Integrative Medicine and Health 2012 \\ Portland, Oregon, USA. 15-18 May 2012
}

\section{Purpose}

The purpose of the study was to develop an objective measure of meditation quality based on the machine classification of multiple simultaneous physiological recordings.

\section{Methods}

We recorded 32-channel EEG, electro-oculogram (EOG), ECG, respiration, and movement from 12 experienced (mean $=13.3$ years of practice) Zen Buddhist meditators and 12 non-meditator controls under two conditions for each group: listening to an audiotape and either loving-kindness meditation (meditators) or sitting quietly (non-meditators). The data were split into 15 minute audiotape and meditation epochs. Data were further divided into training and classification sets, and the support vector machine (SVM)-light algorithm was trained on data from each subject.

\section{Results}

Performance of the SVM classifier is measured as the mean AUC for the receiver operating characteristic on the classification set. Perfect separation is $A U C=1.0$, whereas chance classification is AUC $=0.5$. The best performing feature set across subjects was the respiration signal, AUC $=0.90$. The EEG (based on the 7 common artifact-free channels) and EOG classification performance had mean AUC values of 0.85 and 0.77, respectively. Frequency domain features analyzed included alpha band (mean AUC 0.54) and scalp EMG (mean AUC of 0.68).

\section{Conclusion}

The classifier was able to reliably separate meditating and non-meditating states using the physiological

Oregon Health \& Science University, Portland, USA measures. We were also able to construct a preliminary performance hierarchy of response variables: respiration, EEG, EOG, EMG, and alpha power. The probability of classification can be interpreted as a measure of meditation ability by using the trained classifier to predict class membership in novice meditators. In summary, we have demonstrated a proof-of-concept objective measure of meditation quality.

Published: 12 June 2012

doi:10.1186/1472-6882-12-S1-P3

Cite this article as: McCollough et al.: P01.03. A machine classification measure of meditation ability. BMC Complementary and Alternative Medicine 2012 12(Suppl 1):P3.
Submit your next manuscript to BioMed Central and take full advantage of:

- Convenient online submission

- Thorough peer review

- No space constraints or color figure charges

- Immediate publication on acceptance

- Inclusion in PubMed, CAS, Scopus and Google Scholar

- Research which is freely available for redistribution
() Biomed Central

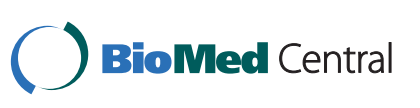

